\title{
A statistical Approach for Finding Influential Factors in Respect of Energy Consuming of A Car Passenger
}

\author{
Hussein M. Ali ${ }^{1}$, Asif lqbal ${ }^{2}$ \\ ${ }^{1}$ Ph.D. in Mechanical Engineering; Tel: +9647708372370; Email: alabadi.hussein@ntu.edu.iq \& hrlha@yahoo.com, Department of Refrigeration \\ and Air conditioning Technology Engineering, Technical Engineering College of Mosul, North Technical University, Mosul, Iraq \\ ${ }^{2}$ Ph.D. in Mechanical Engineering; Tel: +673- 8929497; Email: asifiqbal@gmail.com Faculty of Integrated Technologies, University Brunei \\ Darussalam, Jalan Tungku Link, Bandar Seri Begawan BE1410,Brunei Darussalam
}

\begin{abstract}
Nowadays the usage of gasoline as an energy resource is one of the most important subjects in the engineering field. A car is one type of energy consumer. Energy is used to build the cars and to running it. The fuel prices are fluctuate, so it seems sensible to explore every avenue towards saving energy in cars making. and study the factors that affect its consumption. The aim of the present work is to explain theoretically the calculation of fuel saving and cost in a car passengers in a greater detail than it has been done before and to describe statistically the affecting factors upon it. A statistical analysis has been used to study the influence of the weight and acceleration of the car upon the fuel consumption. It was shown that the fuel consumption increases linearly with the increase of a car weight and accordingly, the cost per unit travel of the car will increase.
\end{abstract}

\section{Nomenclature:}

s.f.c Specific fuel consumption

Fw Attractive force.

Fd Drag force.

FR Friction rolling

Fc Climbing force.

g Gravity acceleration

$\bar{\rho} \quad$ Density of the air

$\mathrm{C} w \quad$ Drag coefficient

$V \quad$ Velocity of the car $(\mathrm{m} / \mathrm{sec})$

$V_{0} \quad$ Velocity of air $(\mathrm{m} / \mathrm{sec})$

$\mathrm{Pw} \quad$ Motive power to resist attractive force

S Travel distance $(\mathrm{m})$

$\mathrm{t} \quad$ Time (sec)

F Total force which run the car

$\mathrm{m} \quad$ Mass of the car $(\mathrm{kg})$

a Acceleration $(\mathrm{m} / \mathrm{sec} 2)$

$\rho \quad$ Density of the fuel

Q Volume of the fuel

S/Q Unit travel of the car per unit volume of fuel (Km/Lit or Mile/gallon)

$\eta \quad$ Transmission system efficiency

\section{Introduction}

Several crises in the world had been resulted in the disappearance of cheap fuel oil. During the last 40 years, there have been many oil price shocks. After these shocks the world had reacted with recession and economies so that, the price was sliding up to unknown levels. Energy is used to build a car and to run it. The energy spent in materials, factories and on the roads. Examination shows that, the energy used to move the cars dominates the energy to produce cars $(15 \%$ of the total energy consumed by nation table 1[1]. With a limited supply of traditional non-renewable energy and a slowly growing renewable energy industry, it is important to increase energy efficiency to meet energy demand. Therefore, it is seem sensible to explore every avenue towards saving the energy used in making \& running cars. Many researchers have carried out the study of the affecting factors on the fuel consumption of automobile. Al-Momani et al (2007)[2], studied experimentally the effect of different factors (tires' conditions, altitudes, passengers' weight and the use of air-conditioning unit (load), vehicle speed, fuel type, maintenance condition) on the vehicles' fuel consumption. They found that the significant improvements in automotive fuel economy can be obtained by reductions in load, aerodynamic drag and rolling resistance (tire improvements), as well as by improvements in maintenance conditions and using efficient fuel type. Charles et al (2013)[3], develop a theoretical model for the rate of fuel consumption of a vehicle (especially of a highway vehicle) as a function of its airspeed, taking into account the fuel consumption due to the moving parts of the vehicle as well. They found that the theoretical model is correctly describe the experimental data on fuel economy of a vehicle as a function of airspeed. The theoretical model as well as the 
experimental data clearly show that the fuel economy of a vehicle does indeed depend on its air speed. Uldis (2011)[4], measured the load as one factor that affect the fuel consumption of a car. He found that the fuel consumption is increasing by increasing the load, every $100 \mathrm{~kg}$ load increases the fuel consumption by 2.58 $2.95 \%$ varying from the driving cycle in on-road, and 2.57- $2.89 \%$ on chassis dynamometer experiments. Jan Rouwendal (1996)[5], analyzed the fuel efficiency of private cars in relation to both the technical characteristics of the cars and the socio-economic characteristics of a driver. This effect has been investigated for a sample of Dutch drivers. He found that the age, type of employment of the driver and the price of the gasoline have significant effects upon the fuel efficiency.

In the present work, a statistical analysis has been used to study the influence of the weight and acceleration of the car upon the fuel consumption. For this purpose, the following guide lines have been followed:

\section{Pre-Experimental Planning}

\subsection{Recognition of system}

For the present study, a car (Golf model 1.3 trim C.CL.GL) of the following technical data has been used [6], is:

Capacity $(1227 \mathrm{~cm} 3)$

Weight of the car $=751.9 \mathrm{Kg}$

S.f.c $-0.34 \mathrm{Kg} / \mathrm{KW} . \mathrm{hr}=9.68 * 10-8 \mathrm{Kg} / \mathrm{w} . \mathrm{sec}$

$\rho=780 \mathrm{~kg} / \mathrm{m} 3$

Face area $=2.2795 \mathrm{~m} 2$

Acceleration $=2.1 \mathrm{~m} / \mathrm{sec} 2$

$\mathrm{f}=0.015$

$\mathrm{C}_{\mathrm{w}}=0.34$

$\eta=0.9$

$V=25 \mathrm{~m} / \mathrm{sec}$

$V_{0}=2.77 \mathrm{~m} / \mathrm{sec}$

\subsection{Theoretical Analysis:}

To understand the factors involved in running the car, the following mathematical analysis have been carried out as shown in Fig. 1.[3],

$F_{w}=F_{c}+F_{R}+F_{d}$

where:

$\mathrm{Fw}=$ attractive force

$\mathrm{Fd}=$ Drag force.

$\mathrm{FR}=$ Friction rolling $=\mathrm{m} * \mathrm{f} * \mathrm{~g}$

$\mathrm{Fc}=$ climbing force.

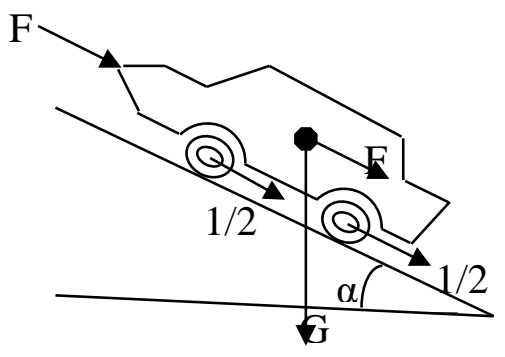

Fig. 1 forces effecting in running the car

After some derivatives for the elements of the above relation both sides of the above equation from zero to t. the following relation was obtained:

$$
\begin{aligned}
& \frac{\eta^{*} Q^{*} \rho}{s . f . c}=s\left(F_{w}+m^{*} a\right) \\
& \frac{Q}{s}=\frac{\left(F_{w}+m^{*} a\right)^{*} s . f . c}{\rho^{*} \eta} \\
& \therefore \frac{s}{Q}=\frac{\rho^{*} \eta}{\left(F_{w}+m^{*} a\right)^{*} s . f . c}
\end{aligned}
$$

where:

$\frac{\mathrm{s}}{Q}=$ unit travel of a car/unit volume of fuel

As shown in the equation above: $\rho, \eta$ and s.f.c Can be regarded as constant Therefore $\frac{s}{Q}$ is a function of a mass of car (m), acceleration (a) and attractive force $\left(F_{w}\right)$.

But:

$$
\begin{aligned}
\mathrm{F}_{\mathrm{w}} & =F_{c}+F_{R}+F_{d} \\
F_{R} & =m^{*} f * g \\
F_{d} & =0.5 \bar{\rho} C_{w} A\left(v+v_{0}\right)^{2} \\
\text { i.e. } & \frac{\mathrm{s}}{Q} \text { vary with } \mathrm{m}, \mathrm{a}, \mathrm{f}, \mathrm{C}_{\mathrm{w}}, A, v, v_{0}
\end{aligned}
$$

\subsection{Choice of factors and selection of the response variable}

In selecting the response variable, we have to be certain that variable completely provides clear, correct and useful information about the process or system that under study. In this experiment, the fuel consumption of a car has been chosen as the response that has to be reviewed. Now, the question is what are the factors that effect upon the fuel consumption of any car?

Actually, there are many factors (controllable, uncontrollable, or noise factors) effect on the fuel consumption of a car, these are: (Weight of the car, Road properties., Maximum speed, Acceleration of the car, Drag force affected by the temperature and air pressure, Aerodynamic shape of a car and Velocity of the wind, etc.). In the present work, it is interested to study the effective of the weight and acceleration of the car that have more effective two factors upon the value of the usage of gasoline by the car. Each of them has special 
levels. We choose those two factors so we can say that there are fixed effect factors. In the first view, it seems that the weight of the car is constant, but it's not true. Because the weight of car is the summation of pure weight of empty car and what is inside in it, including persons and other things in it. Then by changing the car weight from a minimum value (pure empty car weight plus a minimum assumed as driver's weight) to the maximum value of weight that can be held by the car we can find the limitations of the car weight as the factor that must be studied.

The data of this experiment have been chosen randomly and can be shown on the table 1 .

Table 1 Value of S/Q for each experiment. The values in the dark cells are average of each grand cell. The Values unit is $(\mathrm{km} / \mathrm{lit})$

\begin{tabular}{|c|c|c|c|c|c|c|c|c|c|}
\hline & & \multicolumn{8}{|c|}{ acceleration $\left(\mathrm{m} / \mathrm{s}^{2}\right)$} \\
\hline & & \multicolumn{2}{|c|}{2.1} & \multicolumn{2}{|c|}{3.1} & \multicolumn{2}{|c|}{4.1} & \multicolumn{2}{|c|}{5.1} \\
\hline \multirow{8}{*}{ 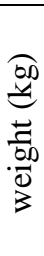 } & \multirow{2}{*}{827} & 4.037 & 4.19 & 2.940 & 3.381 & 2.312 & 2.421 & 1.905 & 2.06 \\
\hline & & $\begin{array}{l}4.356 \\
3750\end{array}$ & 4.19 & 3.821 & 3.381 & 2.529 & 2.421 & $\begin{array}{l}2.225 \\
1758\end{array}$ & \multirow[b]{2}{*}{2.22} \\
\hline & 902 & $\begin{array}{ll}3.752 \\
4.691\end{array}$ & 4.22 & $\begin{array}{l}2.723 \\
3.722\end{array}$ & 3.223 & $\frac{2.137}{2.168}$ & 2.153 & $\frac{1.758}{2.683}$ & \\
\hline & \multirow[b]{2}{*}{977} & 3.504 & \multirow[b]{2}{*}{3.85} & 2.535 & \multirow[b]{2}{*}{2.694} & 1.986 & \multirow{2}{*}{2.480} & 1.632 & \multirow[b]{2}{*}{1.87} \\
\hline & & 4.207 & & 2.852 & & 2.973 & & 2.125 & \\
\hline & 1052 & $\begin{array}{ll}3.287 \\
3.454\end{array}$ & 3.37 & 2.371 & 2.408 & $\begin{array}{l}1.855 \\
1.988\end{array}$ & 1.922 & $\begin{array}{l}1.523 \\
1.676\end{array}$ & 1.600 \\
\hline & \multirow{2}{*}{1127} & 3.096 & \multirow{2}{*}{3.31} & 2.228 & \multirow{2}{*}{2.289} & 1.740 & \multirow{2}{*}{2.099} & 1.427 & \multirow{2}{*}{1.71} \\
\hline & & 3.525 & & 2.350 & & 2.458 & & 1.998 & \\
\hline
\end{tabular}

As shown in table 1, for each situation of the two factors, because of lack of resources and expensiveness of each experiment, we just did two experiments.

In table 1 there are (40) data observed randomly and all of them it will be use. By choosing the response, data, and factors we can be sure about first and important part of the experiments. This means that, the preexperimental planning is complete.

\section{Experimental Design}

\subsection{Choice of experiment}

If the pre-experimental planning activities are done correctly, the choose of experiment becomes relatively easy. In this section we have to select a number of replication and determine which type of design should be used. There are several designs that can be choose to do this experiment but, because of the lack of the resources and expensiveness of the experiments, we have to choose the number of replication as two replicates under each weight and acceleration.

\subsection{Factorial Design}

In this paper, we suspect that there are two factors effect on the response of experiments (fuel consumption of the car) more than the other factors. There are many design experiments involve the study of the effects of two or more factors. In general, factorial designs are most efficient for this type of experiment. By a factorial design, in each replication of experiment, all possible combination of the levels of the factors was investigated[7].

Because of the above reason, we had used factorial design of choice of experimental design in this experiment, and as result the two-factor factorial design applied for experiments. Table 2 shows the basic design of two-factor factorial design.

As shown in table 2 there are two factors, acceleration as factor and has five levels and weight as factor B that has four levels (based on table 1).

Table 2 basic design of two-factor factorial design

\begin{tabular}{|c|c|c|c|c|c|c|c|c|c|}
\hline & \multicolumn{8}{|c|}{ Factor A } \\
\hline & & \multicolumn{2}{|c|}{1} & \multicolumn{2}{|c|}{2} & \multicolumn{2}{|c|}{3} & \multicolumn{2}{|c|}{4} \\
\hline \multirow{10}{*}{ 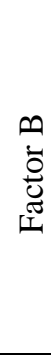 } & \multirow{2}{*}{1} & $y_{111}$ & & $y_{121}$ & & $y_{131}$ & & $y_{141}$ & \\
\hline & & $y_{112}$ & $y_{11}$ & $y_{122}$ & $y_{12 .}$ & $y_{132}$ & $y_{13}$ & $y_{142}$ & $y_{14 .}$ \\
\hline & \multirow{2}{*}{2} & $y_{211}$ & $\bar{y}_{z}$ & $y_{221}$ & $\bar{y}_{z}$ & $y_{231}$ & $y_{2}$ & $y_{241}$ & $y_{-}$ \\
\hline & & $y_{212}$ & $y_{21}$ & $y_{222}$ & $y_{22 .}$ & $y_{232}$ & $y_{23}$ & $y_{242}$ & $y_{24 .}$ \\
\hline & \multirow{2}{*}{3} & $y_{311}$ & $\bar{y}$ & $y_{321}$ & $y_{z}$ & $y_{331}$ & $y_{0}$ & $y_{341}$ & $y$ \\
\hline & & $y_{312}$ & & $y_{322}$ & & $y_{332}$ & & $y_{342}$ & 334. \\
\hline & \multirow{2}{*}{4} & $y_{411}$ & $\bar{y}_{u_{1}}$ & $y_{421}$ & $y_{4}$ & $y_{431}$ & $y_{4}$ & $y_{441}$ & $y_{4}$ \\
\hline & & $y_{412}$ & $y_{41}$ & $y_{422}$ & $y_{42}$ & $y_{432}$ & $\begin{array}{r}y_{43} \\
.\end{array}$ & $y_{442}$ & $y_{44}$ \\
\hline & \multirow{2}{*}{5} & $y_{511}$ & \multirow{2}{*}{$\bar{y}_{51 .}$} & $y_{511}$ & \multirow{2}{*}{$\bar{y}_{52 .}$} & $y_{531}$ & \multirow{2}{*}{$\bar{y}_{53}}$. & $y_{541}$ & \multirow{2}{*}{$\bar{y}_{54 .}$} \\
\hline & & $y_{512}$ & & $y_{522}$ & & $y_{532}$ & & $y_{542}$ & \\
\hline
\end{tabular}

Factor A (weight): has five levels that are:

I. empty car plus driver's weight

II. empty car plus driver's and another person

III. empty car plus driver's and two other persons

IV. empty car plus driver's and three other persons

V. empty car plus driver's and four other persons

Factor B (acceleration): has 4 levels that are:

The values of this factor have been selected according to the acceleration that is in range of factory information:
I. $\quad 2.1^{\left(\mathrm{m} / \mathrm{s}^{2}\right)}$
II. $3.1^{\left(\mathrm{m} / \mathrm{s}^{2}\right)}$
III. $4.1^{\left(\mathrm{m} / \mathrm{s}^{2}\right)}$
IV. $5.1^{\left(m / s^{2}\right)}$

\subsubsection{Formulate effects model and test hypotheses}

The observation in a factorial experiment can be described by a model. In this experiment all factors are fixed, therefore it is easy to test hypotheses and formulate effects model. Also the probability of type one error, $\alpha$, often called the significance level had chosen as 0.05 in this experiment.

For a fixed effect model, test statistics for each main effect and interaction may be constructed by dividing corresponding mean square error. All of these F test will be upper tail, one tail test. The number of degree of freedom for any main effect is the number of levels of the factor minus one, and the number of degree of freedom for an interaction is the product of the number of degrees of freedom associated with the individual components of the interaction. Effects model and testing hypothesis in the following pages.

In this design $a$ is the number of weights that has been used in this research, and $b$ is the number of 
accelerations that has been assumed for the car. The total of each treatment can be shown in table 3 .

Table 3 Totals of each treatment (values in dark cells are average of each interaction treatment)

\begin{tabular}{|c|c|c|c|c|c|c|c|c|c|c|}
\hline & \multicolumn{8}{|c|}{ acceleration $\left(\mathrm{m} / \mathrm{s}^{2}\right)$} & \multirow{3}{*}{$\frac{y_{i . . .}}{24.125}$} \\
\hline & & \multicolumn{2}{|c|}{2.1} & \multicolumn{2}{|c|}{3.1} & \multicolumn{2}{|c|}{4.1} & \multicolumn{2}{|c|}{5.1} & \\
\hline \multirow{5}{*}{ बृ } & 827 & 4.037 & 4.196 & 2.940 & 3.381 & 2.312 & 2.421 & 1.905 & 2.065 & \\
\hline & 902 & 3.752 & 4.222 & 2.723 & 3.223 & 2.137 & 2.153 & 1.758 & 2.221 & 23.634 \\
\hline & 977 & $\begin{array}{l}4.051 \\
.504 \\
1.27\end{array}$ & 3.856 & $\frac{0.1726}{2.535}$ & 2.694 & $\begin{array}{l}2.168 \\
1.986 \\
.20\end{array}$ & 2.480 & $\begin{array}{l}1.683 \\
.632 \\
2\end{array}$ & 1.879 & 21.814 \\
\hline & 1052 & $\begin{array}{l}3.287 \\
3.454\end{array}$ & 3.371 & $\frac{2.371}{2.444}$ & 2.408 & $\begin{array}{l}1.855 \\
1.988\end{array}$ & 1.922 & $\frac{1.523}{1.676}$ & 1.600 & 18.598 \\
\hline & 1127 & $\begin{array}{l}3.096 \\
3.525 \\
\end{array}$ & 3.311 & $\begin{array}{l}2.228 \\
2.350\end{array}$ & 2.289 & $\begin{array}{l}1.740 \\
2.458\end{array}$ & 2.099 & $\begin{array}{l}1.427 \\
1.998\end{array}$ & 1.713 & 18.822 \\
\hline \multicolumn{2}{|c|}{$\mathrm{y}_{\mathrm{j}}$} & \multicolumn{2}{|c|}{37.909} & \multicolumn{2}{|c|}{27.986} & \multicolumn{2}{|c|}{22.146} & \multicolumn{2}{|c|}{18.952} & $y=106.993$ \\
\hline
\end{tabular}

\section{Statistical Analysis}

\subsection{Analysis of the data}

Statistical methods should be used to analyze the data so that results and conclusion are objective rather than judgmental in nature. If the experiment has been designed correctly and if it has been performed according to the design, the statistical methods required are not elaborate. There are many excellent software packages designed to assist in data analysis.

In this paper, Mathematica and MS- Excel has been used to analysis the data. Tables and formulas that construct in the following pages make everything clear to realize steps of analyzing.

\subsection{Analysis of variance (ANOVA)}

Mathematica and MS-Excel for constructing analysis of variance have been used.

The analysis of variance is summarized in table 4 that constructed with Mathematica software package. The primary assumption in this work is $\alpha=0.01$. From the table 4 and the assumption of the $\alpha$ value we can understand that none of the two factors, weight and acceleration, lonely is significantly affecting the fuel consumption of the car. But the interaction of these two factors is significantly affecting the rate of fuel consumption.

Table 4 analysis of variance table

\begin{tabular}{|c|c|c|c|c|c|}
\hline Treatment & SS & DOF & MS & F & P-Value \\
\hline weight & 3.385 & 4 & 0.84625 & 5.038702 & 0.005545 \\
\hline acceleration & 20.805 & 3 & 6.935 & 41.29205 & $9.031^{*} 10^{-9}$ \\
\hline $\begin{array}{c}\text { Interaction of weight and } \\
\text { acceleration }\end{array}$ & 0.95 & 12 & 0.079167 & 0.47137 & 0.903133 \\
\hline error & 3.359 & 20 & 0.16795 & & \\
\hline total & 28.499 & 39 & & & \\
\hline
\end{tabular}

However, to compare the results of each treatment, Tukey method was used to show that each treatment is significantly different from the others or not. To know the answer of this question each pair of the treatments together with the Tukey method is compare as bellow.

The rate of fuel consumption in this project has been shown as unit value of $(\mathrm{km} / \mathrm{lit})$. This means that the best fuel consumption is that value which gives maximum travel distance passed by the car under the same fuel consumed.

PostTests $\rightarrow\{$ Weight

$\rightarrow$ Tukey $\quad\{\{827,1052\},\{902,1052\},\{827,1127\}\}$

According to the above statement that is from Mathematica software, we can understand that there is no significant difference between weight 827,902 , and $977 \mathrm{~kg}$. This shows that we can run the car with $977 \mathrm{~kg}$ weight without sensible change in fuel consumption in compare with the time that we run it with $827 \mathrm{~kg}$ weight. Logically we know that the optimum usage of the car is in the time that we use it with more weight.

PostTests $\rightarrow$ \{Acceleration

$\rightarrow$ Tukey $\{\{2.1,3.1\},\{2.1,4.1\},\{3.1,4.1\},\{2.1,5.1\},\{3.1,5.1\}\}$

According to the above statement that is from Mathematica software, we can understand that there is significant difference between acceleration 2.1 and other accelerations that have been experienced in this project and also we see that the more acceleration, the more fuel consumption is caused. Then the economical acceleration of the car is 2.1 meter per square second.

\subsubsection{Analysis of residual}

After performing analysis of variance, the second step is to check of the normality assumption that could be made by plotting residual histogram. useful procedure is to construct a normal probability plot of the residuals. By using following formulas we can find the residuals, and data of residuals summarized in table 5 .

$$
e_{i j k}=y_{i j k}-\hat{y}_{i j k} \quad \& \quad \hat{y}_{i j k}=\bar{y}_{i j .} \Rightarrow e_{i j k}=y_{i j k}-\bar{y}_{i j} \text {. }
$$

Also in Fig. 2, normality assumption had checked and as it is shown in this figure there is no point outlier. The reason is that, the data have been chosen randomly $\&$ it has variety of scale (quantity).

Table 5 residual versus predicted values

\begin{tabular}{|c|c|c|c|c|c|c|c|}
\hline$y_{i j k}$ & $e_{i j k}$ & $y_{i j k}$ & $e_{i j k}$ & $y_{i j k}$ & $e_{i j k}$ & $y_{i j k}$ & $e_{i j k}$ \\
\hline 4.04 & -0.16 & 2.94 & -0.44 & 2.31 & -0.11 & 1.91 & -0.16 \\
\hline 4.36 & 0.16 & 3.82 & 0.44 & 2.53 & 0.11 & 2.23 & 0.16 \\
\hline 3.75 & -0.47 & 2.72 & -0.50 & 2.14 & -0.02 & 1.76 & -0.46 \\
\hline 4.69 & 0.47 & 3.72 & 0.50 & 2.17 & 0.02 & 2.68 & 0.46 \\
\hline 3.50 & -0.35 & 2.54 & -0.16 & 1.99 & -0.49 & 1.63 & -0.25 \\
\hline 4.21 & 0.35 & 2.85 & 0.16 & 2.97 & 0.49 & 2.13 & 0.25 \\
\hline 3.29 & -0.08 & 2.37 & -0.04 & 1.86 & -0.07 & 1.52 & -0.08 \\
\hline 3.45 & 0.08 & 2.44 & 0.04 & 1.99 & 0.07 & 1.68 & 0.08 \\
\hline 3.10 & -0.21 & 2.23 & -0.06 & 1.74 & -0.36 & 1.43 & -0.29 \\
\hline 3.53 & 0.21 & 2.35 & 0.06 & 2.46 & 0.36 & 2.00 & 0.29 \\
\hline
\end{tabular}

Furthermore in this experiment there is a fixed factor design model so it is possible to use the data without eliminating any data or repeating any experiment.

\subsubsection{Test for equality of variance}

Another assumption that must be satisfied for this experiment is equality of variance. If the model is correct and if the assumptions are satisfied, the residual should be structure less. In this experiment check equality of 
variance by plotting residual versus the predicted values $\hat{y}_{i j k}=\bar{y}_{i j .}$.

As shown in the Fig. 3, there is no obvious pattern so we can conclude that equality of variance satisfied and assumption of homogeneity of variance is not violated.

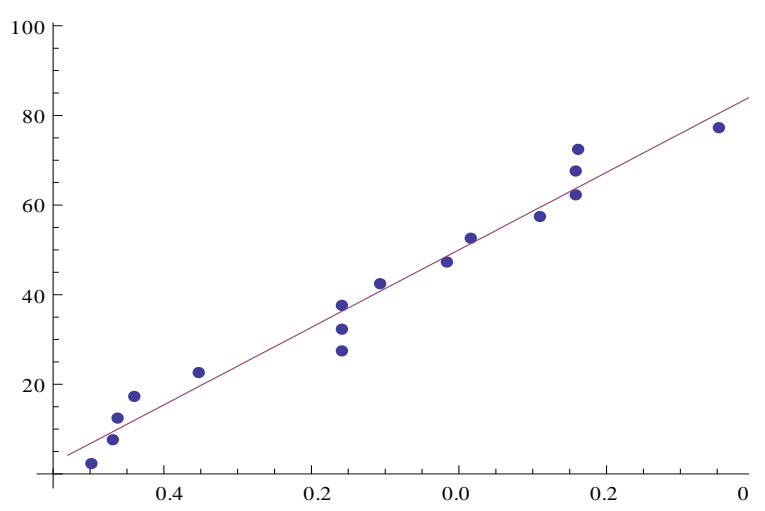

Fig. 2 Normal probability plot of residuals

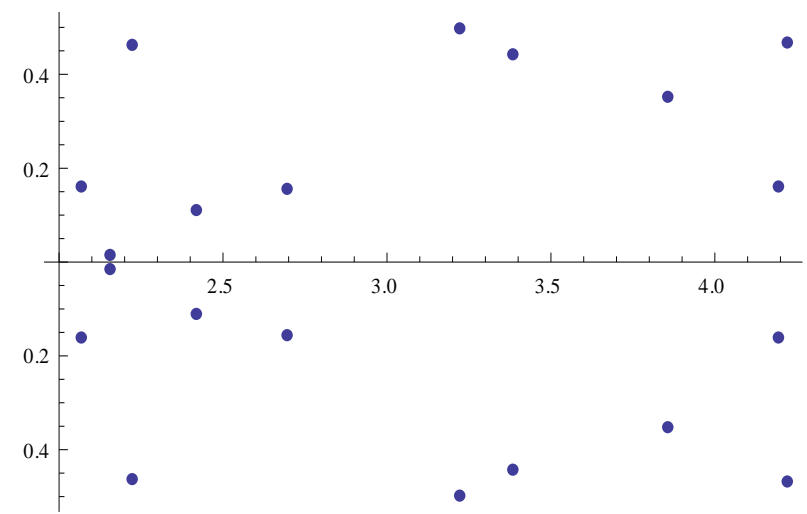

Fig. 3 residual versus predicted values

\section{Conclusions}

The effect of acceleration \& weight of a car on its fuelconsumption had been studied using Design and Analysis of Experiments. By using ANOVA it was shown that the fuel consumption increases with the increase of the car weight. This means, as the mass of the car increases, the travel distance of the car per unit volume of the fuel will decreases and accordingly, the cost per unit travel of the car will increase. As a result of this relation, it seems sensible to explore every avenue towards saving energy in cars making.
Mathematica software was used to obtain this decision in this experiment. The conclusions that have been drawn from the analysis are summarized as follow:

1. The maximum persons that can be in the car without affecting the fuel consumption significantly, is three.

2. The maximum acceleration that is economically is 2.1 meter per square second.

\section{Acknowledgement}

The author would like to thank Assoc. Prof. Dr. Adham Makeia, Department of Industrial Engineering, Eastern Mediterranean University, turkey for his help and support with various issues during doing the work.

\section{References}

1. Royce, king C.S.,"A car for the nineties", BL's energy conservation vehicle, transport engineering, part D, 1984, Vol. 198, No.11, PP. 21-25.

2. Walid. M. Al-Momani, Omar. O. Badran, Experimental Investigation of Factors Affecting Vechicle Fuel Consumption. International Journal of Mechanical and Materials Engineering (IJMME), 2007,Vol. 2 ,No. 2, 180-188

3. Charles $\mathrm{H}$ Heide and Pirooz Mohazzabi, Fuel economy of a vehicle as a function of airspeed: the concept of parallel corridors. International Journal of Energy and Environmental Engineering vol, 2013,Vol 4, No.2

4. Uldis Putnieks, Automobile Fuel Consumption Changes As Effect of Load. Engineering for Rural Development, Jelgava,2013, Vol.5

5. Jan Rouwendal, An Economic Analysis of Fuel Use Per Kilometer By Private Cars. Journal of Transport Economics and Policy.(1996).

6. A shly. M.F. \& Jones R.H. Engineering materials. Materials \& energy in car design, 1980,vol. 34, PP.239-248.

7. D. G. Montgomery, Design and analysis of experiments, Fifth Edition, John Wihley and Sons Inc., 2001. 